\title{
Análise da inserção do tema da violência na Política de Saúde Mental brasileira a partir de seus marcos legais (2001-2011)
}

I ${ }^{1}$ Fabiana Castelo Valadares, ${ }^{2}$ Edinilsa Ramos de Souza I

Resumo: O artigo tem por objetivo descrever e analisar o processo de inserção do tema da violência nos marcos legais da política pública brasileira de saúde mental, com vistas a contribuir para a identificação dos principais desafios e impasses presentes nessa área. Realizou-se análise documental das leis, decretos e portarias publicadas pelo Ministério da Saúde e publicações oficiais da Coordenação de Saúde Mental do ministério emitidas no período de janeiro de 2001 a dezembro de 2011. Observa-se a consolidação de três tendências nesses documentos, denominadas: a violência e a instituição psiquiátrica (2001-2003), marcada pela consolidação dos parâmetros norteadores da política na perspectiva da desinstitucionalização e garantia dos direitos dos indivíduos com transtornos mentais; a violência, o território e suas demandas (2004-2008), onde são identificadas a atenção às vulnerabilidades sociais e a integralidade dos cuidados em saúde; a violência e o desafio do uso prejudicial de álcool e outras drogas (2009-2011), evidenciando situações de risco e violência associadas a esse uso, e acirrando tensões entre forças políticas conservadoras no campo das políticas sociais. Conclui-se que a política de saúde mental adequou-se aos problemas sociais emergentes no país com vistas à promoção da qualidade de vida e a prevenção das violências.

> Palavras-chave: violência; saúde mental; política de saúde mental; análise documental; Brasil.
1 Psicóloga; mestre em

Psicologia Social; doutoranda em Saúde Pública, Escola Nacional de Saúde Pública (ENSP), Fundação Oswaldo Cruz (Fiocruz); pesquisadora colaboradora do Centro Latino-Americano de Estudos de Violência e Saúde Jorge Carelli (CLAVES). Rio de Janeiro, Brasil. Endereço eletrônico: fabianacastelo@yahoo.com.br

2 Doutor em Saúde Pública pela Fiocruz; pesquisadora em Saúde Pública, Fiocruz. Rio de Janeiro, Brasil. Endereço eletrônico: edinilsa@fiocruz.br 


\section{Introdução}

Neste artigo busca-se discutir como o tema da violência se insere na atual política que orienta a atenção em saúde mental no Brasil. Essa política se fundamenta na Reforma Psiquiátrica, que objetivou superar a centralidade manicomial da assistência adotando o modelo baseado na comunidade, capaz de enfrentar os desafios do cuidado às pessoas que sofrem transtornos mentais (DELGADO, 2006).

Os processos que levaram a mudanças profundas na Política de Saúde Mental brasileira têm como antecedentes os movimentos sociais pela redemocratização do país ocorridos na década de 1970. Essa década é considerada por Pitta (2011), como o período da denúncia da hegemonia asilo-manicomial na assistência aos doentes mentais que sofreu grande expansão das internações, sobretudo em instituições privadas conveniadas ao então Instituto Nacional de Previdência Social, criando assim a era da indústria da loucura (PITTA, 2011; AMARANTE, 1995; RESENDE, 1987). Nesse cenário, já próximo aos anos 80 , foram deflagradas graves violaçóes dos direitos dos pacientes internados, que começaram a ganhar corpo nos movimentos sociais de trabalhadores, usuários e familiares, mais tarde intitulado Movimento pela Reforma Psiquiátrica brasileira, reunido em torno da utopia de uma sociedade sem manicômios (AMARANTE, 1995; LOBOSQUE, 2001).

$\mathrm{Na}$ década de 1980, tal movimento possibilitou, entre outras ações, a discussão de questôes sobre a atenção prestada aos portadores de transtornos mentais, envolvendo toda a sociedade, e o encaminhamento de propostas para a efetivação do cuidado extra-hospitalar, a partir da criação dos primeiros Centros de Atenção Psicossocial (CAPS), da realização da primeira grande intervenção em um hospital psiquiátrico privado do país, situado na cidade de Santos - a Casa de Saúde Anchieta - com o objetivo de desinstitucionalização, e da apresentação do projeto de Lei no 3.657/89 (CÂMARA, 1989), que mais tarde se tornou a Lei da Reforma Psiquiátrica. Nos anos 1990, a tramitação desse projeto na Câmara e no Senado foi acompanhada pelo Movimento pela Reforma Psiquiátrica e também reforçada por outros projetos de lei locais e regionais, possibilitando a instalação, em diversas cidades do país, de dispositivos extrahospitalares de atenção territorializados e integrados à comunidade (BORGES; 
BAPTISTA, 2008). No início dos anos 2000, considerado o período da Reforma Legal (PITTA, 2011), ocorreu o processo normativo no qual a Lei $n^{\circ}$ 10.216/2001 e outras direcionadas à qualificação da assistência e ao processo de desinstitucionalização foram aprovadas, conferindo institucionalidade à reforma. Ganharam maior abrangência nessa década a substituição progressiva dos manicômios e a implementação da rede de atenção psicossocial orientada pela plena cidadania das pessoas com transtornos mentais.

No cenário atual, passada uma década da vigência da Lei no 10.216 , novas questôes passaram a incorporar o conjunto de desafios da Reforma Psiquiátrica brasileira, dentre as quais o estigma da loucura e o uso de substâncias psicoativas, identificados ao fenômeno violência, e a precarização do trabalho em saúde pela incorporação das políticas neoliberais no setor (VASCONCELOS, 2010).

Apesar de estar presente na história da humanidade, o fenômeno da violência passou a ser incorporado mais fortemente pelo setor saúde no Brasil a partir dos anos 1980 (MINAYO, 2006; 2008), quando ocorreram mudanças significativas nas taxas de morbimortalidade e as causas externas passaram a figurar entre as principais causas de morte e internações na sociedade. A formalização desse tema no campo da saúde pública brasileira como objeto de intervenção e prevenção ocorreu no ano de 2001, com a Portaria no 737, que instituiu a Política Nacional de Redução da Morbimortalidade por Acidentes e Violências. Nela a violência é definida como "açôes realizadas por indivíduos, grupo, classes, nações, que ocasionam danos físicos, emocionais, morais e ou espirituais a si próprio ou a outros". Segundo Minayo (2009), o fenômeno da violência tem uma polissemia de sentidos, e buscando apresentá-los de forma esquemática, a autora propõe a seguinte tipologia das violências: criminal; estrutural; institucional; interpessoal; intrafamiliar; autoinfligida; e cultural (gênero, racial, contra a pessoa deficiente). As formas de expressão desse fenômeno são as agressões ou abusos físicos, psicológicos, sexuais, e envolvendo negligência, abandono ou privação de cuidados. A política ainda estabelece que toda a rede pública de atenção à saúde deve incorporar a violência como seu objeto de intervenção e prevenção.

No campo da saúde mental, a violência tem se configurado como objeto de trabalho das equipes há muitos anos, principalmente pela iatrogenia das internações psiquiátricas e pela estigmatização da loucura. No entanto, muitas outras expressões da violência estão presentes nesse campo, que vem sendo 
tradicionalmente convocado a incorporar as mazelas e problemas sociais mais amplos (VASCONCELOS, 2010). Assim, conhecer o processo de inserção do tema da violência nos marcos legais que estruturam a atual Política de Saúde Mental brasileira irá subsidiar análises futuras partindo-se da compreensão de que as práticas sociais não são imediatamente adquiridas somente a partir do texto da lei, mas esta sinaliza para os atores sociais o que deve e o que não deve ser feito, bem como a natureza das recompensas e das punições (COSTA et al., 2011).

\section{Métodos}

Este texto é parte de uma pesquisa mais ampla que investigou a inserção do tema da violência na Política Nacional de Saúde Mental brasileira, entendida como o conjunto de intenções presentes na legislação, nos fóruns acadêmicos e publicações científicas, relatórios técnicos, práticas institucionais e espaços de assistência. Para este artigo, foi realizada uma análise documental (CELLARD, 2008) das leis, decretos, portarias e resoluções emitidos pelo Governo Federal brasileiro na área específica da atenção à saúde mental, com o objetivo de compreender o processo de evolução dos conceitos, conhecimentos, comportamentos e práticas da área relacionados à temática da violência.

Os documentos consultados foram publicados de janeiro de 2001 a dezembro de 2011. O acesso ao acervo ocorreu por meio do site oficial do Ministério da Saúde brasileiro, no campo da Coordenação Nacional de Saúde Mental, onde se disponibiliza em biblioteca virtual toda a legislação nacional pertinente ao tema. ${ }^{1}$ O levantamento inicial localizou 240 documentos: sete leis, cinco resoluções, nove decretos e 219 portarias.

Foi realizada a leitura de todos os 240 documentos e selecionados aqueles em que há citação direta do termo violência e/ou referência a seus correlatos (abusos, negligências, agressões, crimes, omissões, etc.). Após esta seleção, foram excluídos 211 documentos, que versam majoritariamente sobre a habilitação e desabilitação de serviços, gestão de recursos e convocações, e nos quais não constavam quaisquer dos termos correlatos buscados. Permaneceram 29 documentos, sendo cinco leis, duas resoluções, três decretos e 19 portarias. Apesar de não constar entre os documentos divulgados na biblioteca virtual, foi incluída a Portaria no 3.088, de 23 de dezembro de 2011, que aborda a construção de estratégias de atenção em saúde para usuários de crack, por sua relevância e atualidade em relação ao tema. 
Também foram considerados os dois relatórios de gestão (BRASIL, 2007; 2011)

divulgados pela Coordenação Nacional de Saúde Mental no período, bem como os relatórios das Conferências Nacionais de Saúde Mental realizadas em 2001 e 2010 (BRASIL, 2002; 2010). No total foram analisados 34 documentos.

Após selecionados, os textos foram lidos e sintetizados, buscando-se identificar os tipos de violência descritos por Minayo (2009): violência institucional; estrutural; cultural; intrafamiliar; criminal; interpessoal; e autoinfligida. Foram também identificados os grupos vulneráveis: portadores de transtornos mentais institucionalizados, crianças e adolescentes, mulheres, usuários de álcool e outras drogas, famílias, idosos, população penitenciária e populações indígenas. Essa análise permitiu agrupar os textos em três períodos: 2001-2003, 2004-2008 e 2009-2011, a partir dos quais serão apresentados os resultados.

A pesquisa contou com o apoio financeiro da Fundação de Amparo à Pesquisa do Estado do Rio de Janeiro (FAPERJ) e seguiu todas as recomendações da Resolução no 196/96 do Conselho Nacional de Saúde (BRASIL, 1996) que dispõem sobre pesquisas com seres humanos.

\section{Resultados e discussão}

Na última década, a Política de Saúde Mental brasileira sofreu mudanças profundas. Houve um processo de democratização da gestão, conferindo participação da sociedade civil nas propostas e diretrizes da política inclusive por via da realização das Conferências de Saúde Mental (BRASIL, 2002; 2010), dos colegiados de coordenadores, da articulação intersetorial da qual participam representantes da Secretaria de Direitos Humanos, Ministério da Justiça, Secretaria Nacional de Economia Solidária, Ministério do Desenvolvimento Social e Combate à Fome, Ministérios da Cultura e da Educação, além das articulações de comitês e grupos de trabalho (BRASIL, 2007; 2011).

Nesse cenário de mudanças, houve também o redirecionamento da atenção passando do modelo hospitalar ao extra-hospitalar (tabela 1), que conta com: a criação de Centros de Atenção Psicossocial (CAPS) e Serviços Residenciais Terapêuticos (SRT), Programa De Volta Para Casa, a redução gradual de leitos em hospitais psiquiátricos e a reestruturação da assistência desses serviços privilegiando instituiçõos de menor porte e de atuação complementar à rede extra-hospitalar. 
Tabela 1. Indicadores de saúde mental segundo dados do Ministério da Saúde em 2002-2010

\begin{tabular}{lcc}
\hline \multicolumn{1}{c}{ Indicadores } & $\mathbf{2 0 0 2}$ & $\mathbf{2 0 1 0}$ \\
\hline Centros de Atenção Psicossocial & 424 & 1.620 \\
Serviços Residenciais Terapêuticos & 85 & 570 \\
Programa De Volta Para Casa & $206^{*}$ & 3.635 \\
Leitos em hospitais psiquiátricos & 51.393 & 32.735 \\
\% de gastos do programa hospitalar & 75,24 & $32,29^{* *}$ \\
\% de gastos do programa extra-hospitalar & 24,76 & $67,71^{* *}$ \\
\hline
\end{tabular}

* O Programa começa em 2003.

** Dados referentes a 2009.

Fonte: Pitta (2011), Brasil (2007 e 2011)

$\mathrm{Na}$ análise inicial, observou-se que a maior parte dos documentos foi emitida unicamente pelo Ministério da Saúde; apenas quatro portarias contaram com a participação de outros ministérios. A gradativa busca pela articulação interministerial na elaboração dos textos analisados parece adotar o conhecimento de que a violência é um fenômeno complexo que deve ser abordado de forma integrada entre diversos setores (NJAINE et al., 2007).

Identificaram-se três distintos períodos que evidenciam a evolução da abordagem do fenômeno violência no âmbito da atenção em saúde mental, definidos como: a violência e a instituição psiquiátrica (2001-2003); a violência, o território e suas demandas (2004-2008); a violência e o desafio do uso prejudicial de álcool e outras drogas (2009-2011). Esses três períodos serão discutidos a seguir.

\section{A violência e a instituição psiquiátrica (2001-2003)}

Os primeiros anos da vigência da Lei no 10.216 foram marcados pela profunda crítica às instituições psiquiátricas. Nesse cenário, a análise do acervo do período de 2001 a 2003 evidencia o processo de implementação da Reforma Psiquiátrica no país, onde são identificadas duas linhas prioritárias de ação: a redução gradual dos leitos psiquiátricos sob a perspectiva da desinstitucionalização e a construção do modelo extra-hospitalar de assistência. 
Em relação à redução gradual dos leitos psiquiátricos, foram formalizados nesse período os parâmetros para a avaliação dos hospitais psiquiátricos estabelecendo critérios para a melhora da qualidade da atenção, como a garantia de um projeto terapêutico individual para cada um dos internos; recursos físicos e humanos atendendo às exigências mínimas previstas nas portarias direcionadas ao setor (Portarias $n^{\circ}$ s 251/2002 e 2.391/2002); e definição da longa permanência (mais de um ano de internação) como aspecto ruim da assistência prestada, entre outros. Também foram restringidas práticas invasivas como a eletroconvulsoterapia, a lobotomia, o choque insulínico, e regulamentadas as internações involuntárias (Lei no 10.216/2001), que passaram a exigir comunicação ao Ministério Público com prazo de até 72 horas.

A reintegração social dos internos em instituições psiquiátricas torna-se diretriz deste novo modelo de assistência, em que o enfrentamento de preconceitos, mitos, práticas e resistências que consideravam as pessoas com transtornos mentais perigosas, incapazes ou inválidas foi alvo de ações específicas, o que se relaciona ao enfrentamento das violências, sobretudo institucional, estrutural e cultural. O Programa De Volta Para Casa (Lei no 10.708/2003) foi responsável por impulsionar o processo de desinstitucionalização, tendo sido criado para apoiar financeiramente os pacientes que passaram longos períodos hospitalizados. Inúmeras portarias foram publicadas habilitando e desabilitando serviços com vistas à implantação da rede de atenção extra-hospitalar e a pactuação de medidas regulatórias da atenção hospitalar. Nesta linha de ação, foi priorizada a população institucionalizada, constituída em sua maior parte de adultos cujo quadro clínico psiquiátrico era considerado cronificado.

Em paralelo, houve a construção do modelo de assistência extra-hospilatar, regulamentada pela Portaria no $336 / 2002$, que definia a estrutura e organização dos Centros de Atenção Psicossocial (CAPS I, II e III) direcionados a adultos portadores de transtornos mentais, crianças e adolescentes (CAPSi), e usuários de álcool e outras drogas (CAPSad). Esses serviços assumiram a função de ordenação da rede de atenção à saúde mental de seu território de abrangência, atuando também no atendimento clínico, suporte à crise, apoio familiar, assistência social, geração de trabalho e renda, e promoção de uma cultura mais inclusiva para os portadores de transtornos mentais (COUTO et al., 2008). 
Nesta portaria, a referência ao tema da violência aparece relacionada à qualidade do atendimento e ao processo de reintegração social.

Apesar da formalização da Portaria no 737/2001, que instituiu a Política Nacional de Redução da Morbimortalidade por Acidentes e Violências (PNRMAV), não se observaram profundas comunicações entre esta e as novas diretrizes da atenção à saúde mental. Nesse período, o termo "violência" não foié explicitado no corpo dos documentos analisados. Assim, a categorização aqui realizada foi a partir de termos como "abuso", "exploração", "acidente", "meios invasivos", "espaços restritivos", "internação involuntária”, entre outros, relacionados ao modelo manicomial de tratamento. De forma geral, o emprego desses termos foi associado às violências institucional, estrutural, cultural, interpessoal, negligências e omissões presentes no estigma da loucura.

O grau de força e o alcance normativo dos documentos aqui referidos carregam implicações distintas. Em relação às duas leis aprovadas nesse período (Leis $n^{\circ} \mathrm{s}$ $10.216 / 2001$ e $10.708 / 2003$ ), apenas a primeira, por seu vasto escopo, exigiu para sua real implementação a edição de diversas portarias, algumas analisadas neste texto. No entanto, tais marcos regulatórios apresentam menor alcance normativo, cabendo a cada gestão sua adequação territorial.

A III Conferência Nacional de Saúde Mental (CNSM), realizada em dezembro de 2001, cumpriu seu objetivo de debater com diferentes membros da sociedade os novos rumos da Política de Saúde Mental no país, o que influenciou a construção de propostas que gradativamente foram incorporadas aos marcos legais. Entre os temas trabalhados, o termo "violência” foi citado em seu relatório final ao qualificar a política anterior como ineficaz, onerosa e violentadora dos direitos humanos fundamentais, e ao propor a atenção intersetorial às vítimas das violências, sua prevenção em instituições de privação de liberdade e de saúde, e ao definir estratégias como o disque-denúncia para os casos de maus-tratos, violência e desassistência a portadores de transtornos mentais. Torna-se possível concluir que a temática da violência presente nos marcos legais da política de saúde mental em construção nesse período é relacionada à mudança das práticas assistenciais até então vigentes no campo da atenção em saúde. 

violência abordado. Período de 2001 a 2003

\begin{tabular}{|c|c|c|c|}
\hline Ano & Documento & Conteúdo & Tipo de Violência \\
\hline 2001 & $\begin{array}{l}\text { Lei no } \\
10.216 \text { de } \\
06 / 04 / 2001\end{array}$ & $\begin{array}{l}\text { Dispõe sobre a proteção } \\
\text { e os direitos das pessoas } \\
\text { portadoras de transtornos } \\
\text { mentais e redireciona o modelo } \\
\text { assistencial em saúde mental. }\end{array}$ & $\begin{array}{l}\text { Estrutural, (termo citado: garantia de } \\
\text { direitos e a proteção das pessoas com } \\
\text { transtornos mentais), Cultural (termo citado: } \\
\text { discriminação), Interpessoal (termo citado: } \\
\text { abuso, opressão), Institucional (termo citado: } \\
\text { garantia de acesso a meios de comunicação, } \\
\text { tratamento pelos meios menos invasivos, } \\
\text { características asilares) } \\
\text { Grupo abordado: pessoas com transtornos } \\
\text { mentais }\end{array}$ \\
\hline \multirow[t]{3}{*}{2002} & $\begin{array}{l}\text { Portaria } \\
\text { GM/MS } \\
\text { no } 251 \text { de } \\
31 / 01 / 2002\end{array}$ & $\begin{array}{l}\text { Estabelece diretrizes e normas } \\
\text { para a assistência hospitalar } \\
\text { em psiquiatria, reclassifica os } \\
\text { hospitais psiquiátricos, define } \\
\text { e estrutura, a porta de entrada } \\
\text { para as internaçốes psiquiátricas } \\
\text { na rede do SUS e dá outras } \\
\text { providências }\end{array}$ & $\begin{array}{l}\text { Estrutural (termo citado: promover a } \\
\text { integração social e assegurar direitos), } \\
\text { Institucional (termo citado: proibida a } \\
\text { existência de espaços restritivos (celas fortes), } \\
\text { inviolabilidade da correspondência dos } \\
\text { pacientes, registro e procedimentos adequados } \\
\text { e com periodicidade, estrutura física e de } \\
\text { pessoal) } \\
\text { Grupo abordado: pessoas com transtornos } \\
\text { mentais }\end{array}$ \\
\hline & $\begin{array}{l}\text { Portaria } \\
\text { GM/MS } \\
\text { no } 336 \text { de } \\
19 / 02 / 2002\end{array}$ & $\begin{array}{l}\text { Estabelece que os Centros de } \\
\text { Atenção Psicossocial poderão } \\
\text { constituir-se nas seguinte } \\
\text { modalidades de serviços: } \\
\text { CAPS I, II, III, definidos por } \\
\text { ordem crescente de porte/ } \\
\text { complexidade e abrangência } \\
\text { populacional, conforme } \\
\text { disposto nesta portaria }\end{array}$ & $\begin{array}{l}\text { Estrutural (termo citado: necessidade } \\
\text { de proteção e os direitos da pessoa com } \\
\text { transtornos mentais), Institucional (termo } \\
\text { citado: funcionamento independente da } \\
\text { estrutura hospitalar, [serviços] capacitados } \\
\text { para o acompanhamento dos pacientes) } \\
\text { Grupo abordado: pessoas com transtornos } \\
\text { mentais }\end{array}$ \\
\hline & $\begin{array}{l}\text { Portaria } \\
\text { GM/MS } \\
\text { no } 2.391 \text { de } \\
26 / 12 / 2002\end{array}$ & $\begin{array}{l}\text { Regulamenta o controle das } \\
\text { internaçóes psiquiátricas } \\
\text { involuntárias (IPI) e voluntárias } \\
\text { (IPV) de acordo com o disposto } \\
\text { na lei } 10216 \text {, de } 06 / 04 / 2002 \text {, } \\
\text { e os procedimentos de } \\
\text { notificação da comunicação } \\
\text { das IPI e IPV ao ministério } \\
\text { público pelos estabelecimentos } \\
\text { de saúde, integrantes ou não do } \\
\text { SUS. (Ementa elaborada pela } \\
\text { CDI/MS) }\end{array}$ & $\begin{array}{l}\text { Estrutural (termo citado: proteção e os } \\
\text { direitos das pessoas com transtornos mentais), } \\
\text { Institucional (termo citado: caracteriza quatro } \\
\text { modalidades de internação [visa reprimir } \\
\text { abusos da internação involuntária]), } \\
\text { Grupo abordado: pessoas com transtornos } \\
\text { mentais }\end{array}$ \\
\hline 2003 & $\begin{array}{l}\text { Lei no } \\
10.708 \text { de } \\
31 / 07 / 2003\end{array}$ & $\begin{array}{l}\text { Institui o auxílio-reabilitação } \\
\text { psicossocial para pacientes } \\
\text { acometidos de transtornos } \\
\text { mentais egressos de internações. }\end{array}$ & $\begin{array}{l}\text { Estrutural (termo citado: o auxilio é parte de } \\
\text { um programa de ressocialização) } \\
\text { Grupo abordado: pessoas com transtornos } \\
\text { mentais }\end{array}$ \\
\hline
\end{tabular}

Fonte: elaboração própria. 
A violência, o território e suas demandas (2004-2008)

A partir de 2004, o termo "violência" começou a ser evidenciado no acervo. Aumentou para dez o número de marcos regulatórios abordando direta e indiretamente essa temática, assim como se diversificam as tipologias da violência neles citadas.

\section{Quadro 2. Relação de documentos, ano e tipo de violência abordados no período} de 2004 a 2008

\begin{tabular}{|c|c|c|c|}
\hline Ano & Documento & Conteúdo & Tipo de Violência \\
\hline 2004 & $\begin{array}{l}\text { Portaria GM/ } \\
\text { MS no } 2.607 \\
\text { de } 10 / 12 / 2004\end{array}$ & $\begin{array}{l}\text { Aprova o Plano } \\
\text { Nacional de Saúde/PNS } \\
\text { - Um Pacto pela Saúde } \\
\text { no Brasil. }\end{array}$ & $\begin{array}{l}\text { Estrutural (termo citado: desigualdade em } \\
\text { saúde, desigualdade financeira, combate a fome), } \\
\text { Intrafamiliar (termo citado: maus tratos, violência } \\
\text { contra crianças e deficientes, violência intrafamiliar), } \\
\text { Interpessoal (termo citado: acidente de trânsito, } \\
\text { homicídios, abuso sexual, agressōes), Criminal } \\
\text { (termo citado: exploração sexual), Cultural } \\
\text { (termo citado: violência de gênero, étnico/racial), } \\
\text { Autoinfligida (termo citado: suicídio) } \\
\text { Grupos abordados: crianças, adolescentes, pessoas } \\
\text { em privação de liberdade (sistema socioeducativo, } \\
\text { prisôes, asilos), mulheres, pessoas com transtornos } \\
\text { mentais, indígenas, quilombolas, negros, } \\
\text { trabalhadores rurais, usuários de drogas, pessoas em } \\
\text { situação de rua, idosos, homossexuais, pessoas com } \\
\text { deficiência, autores de violência }\end{array}$ \\
\hline 2005 & $\begin{array}{l}\text { Portaria GM/ } \\
\text { MS no } 1.027 \text { de } \\
01 / 07 / 2005\end{array}$ & $\begin{array}{l}\text { Aprova normas de } \\
\text { funcionamento e } \\
\text { credenciamento/ } \\
\text { habilitação dos } \\
\text { serviços hospitalares de } \\
\text { referencia para atenção } \\
\text { integral aos usuários de } \\
\text { álcool e outras drogas }\end{array}$ & $\begin{array}{l}\text { Institucional (termos citados: resguardar o usuário, } \\
\text { garantia de atenção integral,), Autoinfligida (termo } \\
\text { citado: lesos autoinfligidas, tentativas de suicídio), } \\
\text { Interpessoal (termo citado: lesōes por terceiros, } \\
\text { heteroagressividade) } \\
\text { Grupo abordado: usuários de álcool e outras drogas }\end{array}$ \\
\hline & $\begin{array}{l}\text { Portaria GM/ } \\
\text { MS no } 1.028 \text { de } \\
01 / 07 / 2005\end{array}$ & $\begin{array}{l}\text { Determina que as ações } \\
\text { que visam à reduçâo de } \\
\text { danos sociais e à saúde, } \\
\text { decorrentes do uso de } \\
\text { produtos, substâncias } \\
\text { ou drogas que causem } \\
\text { dependência }\end{array}$ & $\begin{array}{l}\text { Estrutural (termo citado: garantia para o exercício } \\
\text { de direitos), Interpessoal (termo citado: acidentes de } \\
\text { trânsito, exposiçãa a sexo desprotegido) } \\
\text { Grupos abordados: jovens, adolescentes, pessoas em } \\
\text { privação de liberdade }\end{array}$ \\
\hline & $\begin{array}{l}\text { Portaria GM/ } \\
\text { MS no } 2.542 \text { de } \\
22 / 12 / 2005\end{array}$ & $\begin{array}{l}\text { Institui grupo de } \\
\text { trabalho com o objetivo } \\
\text { de elaborar e implantar } \\
\text { a Estratégia Nacional de } \\
\text { Prevençãa ao Suicídio }\end{array}$ & $\begin{array}{l}\text { Autoinfligida (termo citado: suicídio), Interpessoal } \\
\text { (termo citado: violência sexual) } \\
\text { Grupos abordados: todos }\end{array}$ \\
\hline
\end{tabular}




\begin{tabular}{|c|c|c|c|}
\hline Ano & Documento & Conteúdo & Tipo de Violência \\
\hline 2006 & $\begin{array}{l}\text { Portaria } \\
\text { Interministerial } \\
\text { PR/MS no } \\
1.055 \text { de } \\
17 / 05 / 2006\end{array}$ & $\begin{array}{l}\text { Institui grupo de } \\
\text { trabalho para viabilizar } \\
\text { a constituição do } \\
\text { Núcleo Brasileiro de } \\
\text { Direitos Humanos e } \\
\text { Saúde Mental. }\end{array}$ & $\begin{array}{l}\text { Violência institucional } \\
\text { Grupo abordado: pessoas com transtornos mentais }\end{array}$ \\
\hline & $\begin{array}{l}\text { Portaria GM/ } \\
\text { MS no } 1.8076 \\
\text { de } 14 / 08 / 2006\end{array}$ & $\begin{array}{l}\text { Institui Diretrizes } \\
\text { Nacionais para } \\
\text { Prevenção do Suicídio, } \\
\text { a ser implantadas em } \\
\text { todas as unidades } \\
\text { federadas, respeitadas } \\
\text { as competências das três } \\
\text { esferas de gestão }\end{array}$ & $\begin{array}{l}\text { Autoinfligida } \\
\text { Grupo abordado: todos }\end{array}$ \\
\hline & $\begin{array}{l}\text { Lei no } 11.343 \\
\text { de } 23 / 08 / 2006\end{array}$ & $\begin{array}{l}\text { Institui o Sistema } \\
\text { Nacional de Políticas } \\
\text { Públicas sobre Drogas } \\
\text { - Sisnad; prescreve } \\
\text { medidas para prevenção } \\
\text { do uso indevido, atenção } \\
\text { e reinserção social de } \\
\text { usuários e dependentes } \\
\text { de drogas; estabelece } \\
\text { normas para repressão à } \\
\text { produção não autorizada } \\
\text { e ao trafico ilícito de } \\
\text { drogas; define crimes e } \\
\text { dá outras providências }\end{array}$ & $\begin{array}{l}\text { Estrutural (termo citado: garantia de direitos } \\
\text { fundamentais e inclusão social), Criminal (termo } \\
\text { citado: tráfico ilícito de drogas, crimes) } \\
\text { Grupo abordado: todos }\end{array}$ \\
\hline \multirow[t]{2}{*}{2007} & $\begin{array}{l}\text { Decreto } n^{\circ} \\
6.117 \text { de } \\
22 / 05 / 2007\end{array}$ & $\begin{array}{l}\text { Aprova a Política } \\
\text { Nacional sobre o Álcool, } \\
\text { dispōe sobre as medidas } \\
\text { para redução do uso } \\
\text { indevido de álcool e } \\
\text { sua associação com a } \\
\text { violência e criminalidade, } \\
\text { e dá outras providências }\end{array}$ & $\begin{array}{l}\text { Criminal (termo cotado: violência e criminalidade) } \\
\text { Interpessoal (termo citado: agressões, violência no } \\
\text { trânsito), Intrafamiliar } \\
\text { Grupo abordado: jovens, população indígena, } \\
\text { motoristas }\end{array}$ \\
\hline & $\begin{array}{l}\text { Portaria GM/ } \\
\text { MS no } 2759 \text { de } \\
25 / 10 / 2007\end{array}$ & $\begin{array}{l}\text { Estabelece diretrizes } \\
\text { gerais para a Política de } \\
\text { Atenção Integral à Saúde } \\
\text { Mental das Populações } \\
\text { Indígenas e cria o } \\
\text { Comitê Gestor }\end{array}$ & $\begin{array}{l}\text { Cultural (termo citado: respeitar seus valores, } \\
\text { economias, tecnologias, modos de comunicação e } \\
\text { expressão), Autoinfligida (termo citado: suicídio) } \\
\text { Grupo abordado: populações indígenas }\end{array}$ \\
\hline 2008 & $\begin{array}{l}\text { Portaria GM/ } \\
\text { MS nº154 de } \\
24 / 01 / 2008\end{array}$ & $\begin{array}{l}\text { Cria os Núcleos de } \\
\text { Apoio à Saúde da } \\
\text { Família - NASF }\end{array}$ & $\begin{array}{l}\text { Estrutural (termo citado: estimular a inclusão social, } \\
\text { combate à violência), Cultural (termo citado: combate } \\
\text { a discriminação contra usuários de drogas, egresso do } \\
\text { sistema prisional, portadores de transtornos mentais), } \\
\text { Autoinfligida (termo citado: suicídio), Intrafamiliar } \\
\text { (termo citado: violência intrafamiliar) } \\
\text { Grupo abordado: famílias }\end{array}$ \\
\hline
\end{tabular}

Fonte: elaboração própria. 
Apesar de não estar inserida entre as portarias da área da saúde mental, em maio de 2004 foi publicada a Portaria GM/MS no 936/2004, que criou a Rede de Núcleos de Prevenção da Violência e Promoção da Saúde. Esta portaria teve como objetivo viabilizar a implementação da PNRMAV de 2001, definindo como estratégia a dotação de recursos em projetos municipais com ênfase na prevenção, e convocando os gestores locais ao enfrentamento das violências.

Nesse contexto, a aprovação do Pacto pela Saúde (Portaria GM/MS no 2607), em dezembro de 2004, estabeleceu como diretriz a atenção no território e a integração das ações de saúde mental à atenção básica. $\mathrm{O}$ processo teve como efeito a aproximação da atenção em saúde mental com o território de relações, subjetividades, tensões e vulnerabilidades presentes no rol de possibilidades da vida humana. Esse processo de capilarização da atenção em saúde mental, integrado e próximo à comunidade, passou então a revelar problemas antes pouco visíveis, como os casos de violência.

Entre as linhas de ação definidas no pacto, destacam-se a redução da morbimortalidade por acidentes e violências, e a realização de ações voltadas para a prevenção desses agravos. Neste, as referências à violência davam ênfase às violências estrutural e cultural, com foco nas situações de pobreza e vulnerabilidade social enfrentadas a partir de estratégias de combate à fome e promoção da adoção de comportamentos e ambientes seguros e saudáveis. Em relação à violência cultural, considerava crianças e idosos, visando à perspectiva geracional como grupos prioritários, além das questões de gênero e racial, inclusive as populações indígenas. Preconizava, ainda, que tanto as vítimas quanto os autores de violência devem receber atendimento na rede de saúde mental, buscando uma abordagem integral. Foram adotados como foco de intervenção da atenção à saúde mental os grupos vulneráveis aos homicídios, acidentes de trânsito e suicídios, as violências intrafamiliares e institucionais. Finalmente, eram alvos dos marcos regulatórios as intervençõos nos casos de exploração sexual de crianças e adolescentes.

A partir do Pacto pela Saúde, foram são identificadas três linhas de ação entre os documentos analisados no período de 2004 a 2008: a atenção aos usuários de álcool e outras drogas; a prevenção do suicídio; e a atenção integral à família.

Considerando a linha de ação da atenção aos usuários de álcool e outras drogas, a partir de 2005, a temática passou a ser alvo de grande parte dos 
documentos analisados, evidenciando a complexidade do tema e a magnitude epidemiológica dos problemas a ele associados. O período foi caracterizado pelos debates e formalizações no cenário nacional dos parâmetros para a atenção a esse público. Neste sentido, em 2005 foram aprovados e credenciados os hospitais habilitados para atenção integral à crise para usuários de álcool e outras drogas (Portaria GM/MS no 1.027/2005), e a redução de danos foi definida como orientação política (Portaria GM/MS no 1.028/2005). Em relação à violência, essas portarias visavam por um lado, garantir a qualidade da atenção em saúde mental, estabelecendo critérios rígidos para a habilitação de serviços, e tomando como norte os direitos do portador de transtornos mentais preconizados pela Reforma Psiquiátrica. Por outro, apontavam um conjunto de violências presentes nos casos de uso prejudicial de álcool e outras drogas como as interpessoais (as agressões e homicídios, e no trânsito, principalmente, pela associação entre álcool e direção), criminais (relacionadas ao tráfico de drogas, delinquência e exploração sexual), autoinfligidas (suicídios e tentativas).

Em 2006, com a criação do Sistema Nacional de Políticas sobre Drogas (Sisnad - Lei no 11.343/2006), formalizou-se uma abordagem intersetorial para a questão do uso prejudicial. Com o olhar implicado sobre o tema da violência, essa lei focalizava duas questóes fundamentais: o enfrentamento do preconceito social aos usuários de drogas, preconizando a garantia da atenção integral à saúde e a reabilitação social (violência estrutural); e a violência criminal relativa ao porte, venda e cultivo de drogas ilícitas, em associação ou não com a questão do tráfico de drogas.

Em 2007, a questão do uso indevido de álcool foi trabalhada em um documento específico (Decreto no 6.117/2007), a Política Nacional sobre Álcool, onde eram apresentados os fundamentos para a sustentação da estratégia de enfrentamento coletivo e intersetorial dos problemas a ele relacionados. $\mathrm{O}$ decreto abordava os danos sociais associados ao uso prejudicial de álcool, como a violência intrafamiliar, interpessoal (agressões e homicídios, e a violência no trânsito), criminal (relacionadas a abusos e exploração sexual e ao trabalho infantil).

A violência no trânsito ganhou bastante relevo no período, sendo alvo de ações específicas não somente do campo da saúde. Em 2008, foi aprovada a reformulação do Código Nacional de Trânsito Brasileiro (Lei no 11.705/2008), 
que reduziu a zero os níveis de tolerância para alcoolemia no trânsito, sendo seu impacto na redução das taxas de morbimortalidade por acidentes de trânsito comemorado no ano seguinte à sua vigência (BRASL, 2009), mas novamente questionado nos anos subsequentes, com novo crescimento das taxas.

A abordagem preventiva em relação à temática da violência ganha maior destaque na linha de ação relacionada aos suicídios. A partir de 2005, com a criação de um grupo de trabalho sobre o tema (Portaria GM/MS no 2.542/2005), e em 2006, com a aprovação da Diretriz Nacional para a Prevenção do Suicídio (Portaria GM/MS no 1.786/2006), foi estabelecida a proposta de atuação para toda a rede de atenção à saúde, em especial a saúde mental. Definiu-se a proposta de intervenção frente a grupos vulneráveis como: pacientes psiquiátricos, pessoas institucionalizadas (em hospitais, asilos, presídios, sistema socioeducativo), moradores de rua, vítimas de violência sexual, usuários de drogas, trabalhadores rurais expostos a agentes tóxicos ou em condições de risco de vida, portadores de doenças crônicas e populações indígenas.

Apesar de não estarem associadas apenas ao problema do suicídio, mais duas portarias apontam esse tema ao tratarem da violência institucional (Portaria Interministerial $\left.\mathrm{n}^{\circ} 1.055 / 2006\right)$, e a atenção de saúde mental a populações indígenas (Portaria GM/MS no 2.759/2007). Além da violência autoinfligida, as portarias expõem a violência cultural e seus impactos na manutenção da qualidade de vida.

Em relação à estratégia de atenção integral a família, observa-se que a pauta começa a ser traçada em 2004 e é novamente formalizada em 2008, com a criação dos Núcleos de Apoio à Saúde da Família (NASF), por meio da Portaria GM/MS no 154/2008. O objetivo dos NASFs é fortalecer a Estratégia Saúde da Família na promoção da atenção básica. O documento aponta que as ações desse serviço devem contemplar a inclusão social e a prevenção da violência estrutural, cultural, intrafamiliar e autoinfligida.

Neste segundo período, percebe-se um processo de maior apropriação das questôes sociais, em especial do tema da violência, como objetos de intervenção e 
prevenção por parte dos serviços de saúde. Nesse sentido, a área da saúde mental

surge como meio de ação e intervenção na realidade social, incorporando assim, em suas práticas cotidianas, a temática da violência.

Cabe destacar aqui a força normativa dos documentos então aprovados. Apenas a Lei no 11.343/2006 foi aprovada nesse período, abordando mais diretamente a temática do uso indevido de drogas. Essa lei apresentava um texto bem menos progressista que a Portaria GM/MS no 1.028/2005, que trazia a perspectiva da redução de danos como norteadora da Política de Saúde Mental. Como lei aquela apresentava maior alcance normativo, evidenciando o caráter punitivo definido em seu texto, por sua vez as demais portarias aprovadas no período exigiam maior comprometimento do gestor local, o que pode comprometer sua real implementação.

\section{A violência e o desafio do uso prejudicial de álcool e outras drogas (2009-2011)}

A partir de 2009, observou-se um maior volume de documentos relacionados à temática da violência. A maior preocupação com o tema é inclusive evidenciada no relatório final da IV Conferência Nacional de Saúde Mental, realizada em 2010, que contempla um tópico específico denominado "Violência e Saúde Mental" em um dos eixos de discussão. Nele foram abordadas questôes como a necessidade de capacitação das equipes para identificação precoce dos casos de violência; criação de mecanismos de denúncia; garantia de apoio integral a todos os envolvidos; atuação intersetorial da rede; construção de estratégias de sensibilização da população em geral abordando vulnerabilidades de grupos específicos; construção de açôes intersetoriais voltadas para a prevenção, entre outras. O uso prejudicial de álcool e outras drogas passou a ser mais enfaticamente abordado, envolvendo contextos de criminalidade, exploração sexual e comercial de crianças e adolescentes, negligências, omissões e suicídios. Neste período também foram tratados, se bem que de forma pontual, os temas da violência intrafamiliar (Lei no 12.318/2010) e criminal (Resolução CNPCP/MJ no 4/2010). 

de 2009 a 2010

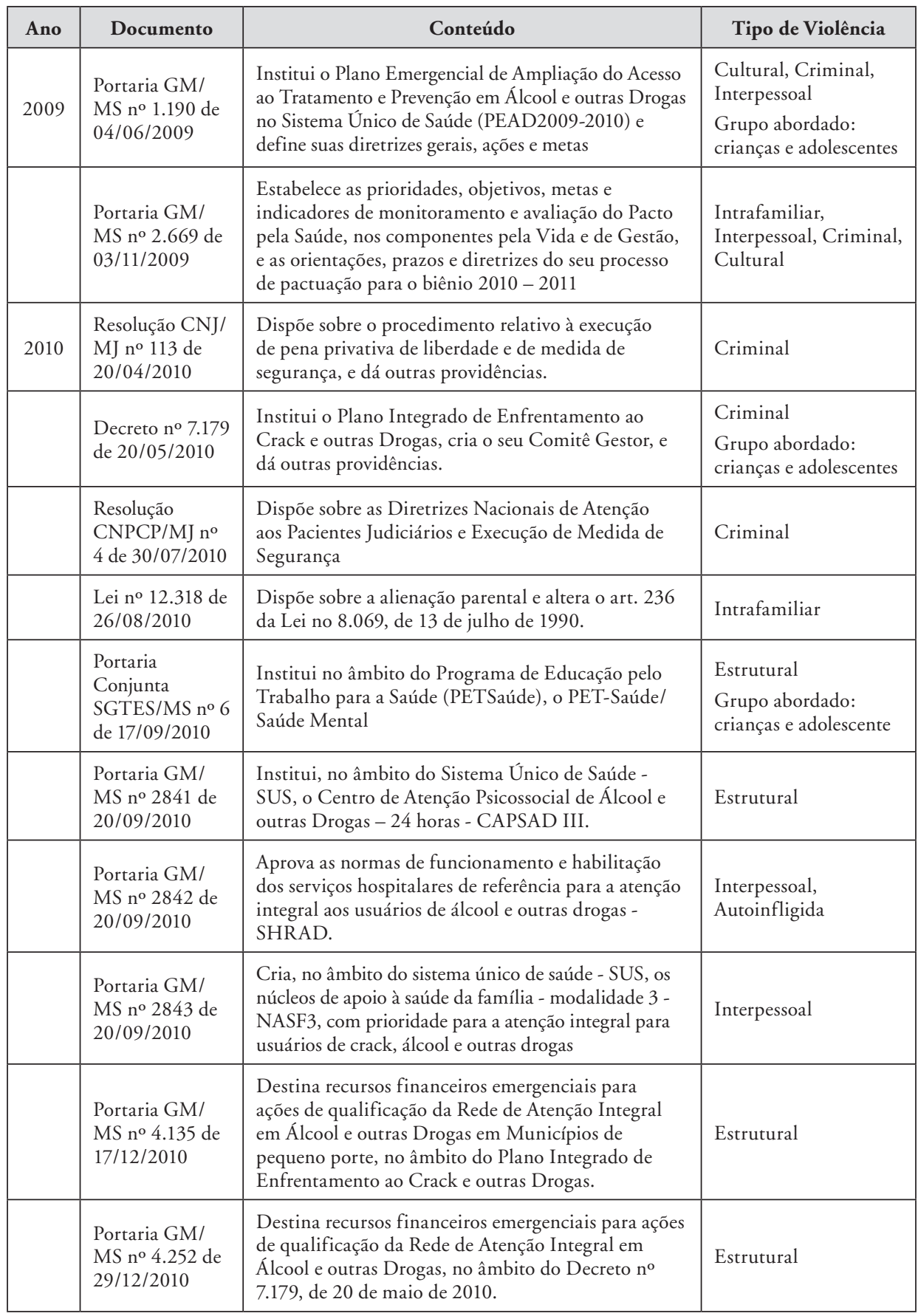

Fonte: elaboração própria. 
Movido pelas mudanças no cenário epidemiológico brasileiro, que mostra a expansão do consumo de substâncias como álcool e outras drogas (principalmente a pasta-base, crack e merla) associado a contextos de vulnerabilidade de crianças, adolescentes e jovens, foi criado em 2009 o Plano Emergencial de Ampliação do Acesso ao Tratamento e Prevenção em Álcool e outras Drogas no Sistema Único de Saúde (Portaria GM/MS no 1.190/2009). Seus objetivos eram promover a garantia de tratamento na rede pública de saúde, adotar ações orientadas para a prevenção do uso prejudicial de álcool e outras drogas, integrar de forma sustentável as políticas visando a promoção da saúde e redução dos riscos associados. O plano tratava da discriminação e do preconceito na abordagem aos usuários de drogas, as diversas violências perpetradas contra crianças e adolescentes (intrafamiliar, abusos físico e psicológico, exploração sexual), além das violências interpessoal e criminal.

Percebe-se um movimento de estruturação da rede de atendimento aos usuários de álcool e outras drogas, com a criação de serviços e estratégias direcionados a este público. Assim, ainda em 2009, o novo Pacto pela Saúde (Portaria GM/ MS no 2.669/2009) reafirmava o comprometimento da saúde mental na atenção básica e a necessidade de adoção e ampliação das ações de prevenção das violências e apoio aos grupos vulneráveis. Esta linha de ação também passou a considerar os idosos como grupo específico e vulnerável à violência (Lei no 12.461, de 26/07/2011), que prevê a notificação de todos os casos suspeitos e confirmados de violência contra esse público. Antes, em 2010, as ações direcionadas à atenção a crianças e adolescentes e usuários de drogas foram alvo de regulamentações específicas que visavam ampliar a rede de atendimento, com abertura de leitos especializados, acompanhamento sociofamiliar, capacitação permanente de profissionais, melhora da qualidade da informação em saúde e combate ao tráfico de drogas (Decreto no 7.179/2010 e Resolução no 4/2010). A criação dos serviços CAPSad III de atendimento 24 horas (Portaria GM/MS no 2.841/2010) e NASF III (Portaria GM/MS no 2.843/2010) e a habilitação dos Serviços Hospitalares de Referência para Atenção Integral Álcool e Drogas (SHRAD) (Portaria GM/ MS no 2.842/2010) vieram para dar o suporte necessário à rede de atendimento. Por sua vez, a capacitação dos profissionais dessa rede foi alvo de financiamento (Portarias GM/MS no 4.135 e 4.252) e do Programa Educação pelo Trabalho para a Saúde (Portaria Conjunta Secretaria de Gestão do Trabalho e da Educação na Saúde SGTES/MS nº 6/2010). 
Em 2011, frente à maior pressão da sociedade e da mídia em relação à temática do uso prejudicial de substâncias psicoativas, principalmente o crack, dois documentos foram publicados visando reestruturar a gestão (Decreto $\mathrm{n}^{\mathrm{o}}$ 7.426, de 07/01/2011) e ampliar e formalizar os dispositivos de atenção aos usuários (Portaria no 3.088, de 23/12/2011). Ambos os documentos sinalizam para um cenário menos progressista em relação aos preceitos da Reforma Psiquiátrica, o que demonstra a crescente força política de grupos e corporaçōes médicas, farmacêuticas e religiosas atualmente no país. O primeiro documento estabelece a diretriz que norteia as açōes relativas ao tema das drogas, passando a privilegiar políticas repressoras no âmbito da Justiça e da Segurança Pública, em detrimento das ações interministeriais. Já o segundo, apesar de instituir a Rede de Atenção Psicossocial para pessoas com sofrimento ou transtorno mental e com necessidades decorrentes do uso de crack, álcool e outras drogas, no âmbito do Sistema Único de Saúde, formalizou: a criação de serviços como CAPSad III de funcionamento 24h; e a ampliação dos leitos de atenção integral em hospitais gerais, os Consultórios de Rua integrados à Atenção Básica de Saúde, e as unidades de acolhimento 24 horas de caráter protetivo, em ambiente residencial, para pessoas que apresentam condição de vulnerabilidade social e familiar. Também autorizou o financiamento público das Comunidades Terapêuticas, ação considerada, pelo movimento da Reforma Psiquiátrica, como grande retrocesso da política, uma vez que são conhecidas as graves violações de direitos presentes nessas comunidades e retratadas em relatório de fiscalização (CFP, 2011) além do caráter excludente, estigmatizante e repressor deste tipo de serviço.

Diante do conjunto de açôes analisadas, compreende-se que há um processo de aprimoramento das estratégias de atenção em saúde mental, sensíveis às demandas sociais emergentes no país. Nesse sentido, como apresentado no Relatório de Gestão 2007-2010 (BRASIL, 2011), a temática do uso prejudicial de álcool e outras drogas exerceu grande pressão na rede de atendimento, inicialmente pouco habilitada. Este fato contribuiu para que um conjunto de estratégias fosse desenvolvido visando estruturar e organizar os serviços, além da capacitação de profissionais para atuarem frente ao tema, mas também possibilitou que práticas já superadas fossem reeditadas, fortalecendo preconceitos e permitindo abusos (violência institucional e cultural). 


\section{Conclusão}

O processo de inserção do tema da violência nos marcos legais da Política de Saúde Mental brasileira foi analisado neste artigo considerando o período e as principais questóes abordadas. Nesse sentido, pode-se perceber que a agenda da saúde mental foi gradativamente introduzindo a temática da violência como objeto de intervenção da sua rede de serviços. No entanto, cabe destacar que a inserção do tema nos marcos legais reflete apenas parte do processo de construção da política de atenção a saúde mental, o que não garante a imediata adoção de suas diretrizes nas práticas pertinentes à produção científica, aos fóruns institucionais e à atenção psicossocial, que devem ser analisadas nestes contextos específicos em futuros estudos.

Pode-se constatar, portanto, que no início da década, quando a reorientação do modelo de assistência estava em processo de construção, a temática da violência institucional servia como apoio para a implementação de um modelo de atenção mais humano, que valorizava os direitos dos usuários. Já no período seguinte, o processo de capilarização da rede de atenção em saúde mental revelou a complexidade da atenção no território. Isto é, o território, assim como os manicômios de anos atrás, convocava a rede de atendimento a buscar soluçóes para as questôes sociais que interferissem na promoção da saúde, exigindo desta rede a integralidade dos cuidados.

As distintas formas de violência reveladas nos documentos desse período apontam para temas sempre presentes na história brasileira, mas até então pouco abordados como objeto de intervenção no âmbito da saúde, como a violência interpessoal, autoinfligida e cultural. $\mathrm{O}$ terceiro momento destaca a necessidade de reorganização da rede de saúde mental, para a atenção às questōes sociais emergentes. O problema do uso prejudicial de álcool e outras drogas surge nesse contexto pressionando a área de saúde mental a encontrar soluções para uma realidade complexa. Assim, é a atenção à questão do uso prejudicial de álcool e outras drogas que revela uma imbricada rede de violências e interesses associados, exigindo respostas cada vez mais intersetoriais.

É importante atentar para os retrocessos da Política de Saúde Mental nos últimos anos, marcados pela presença de iniciativas repressoras e judiciais no 
campo da atenção à saúde. Tais medidas emergem num cenário social de crise e refletem anseios da sociedade quanto a "soluções fáceis" de problemas complexos que reeditam a exclusão social como "forma de tratamento". Nesse cenário, os movimentos pela Reforma Psiquiátrica demandam maiores mobilizações, mas também enfrentam, sobretudo por parte dos trabalhadores da saúde, as forças das políticas neoliberais que fragilizam os vínculos de trabalho e promovem a rotatividade das equipes tendo como efeitos a desmobilização do movimento. ${ }^{2}$

\section{Agradecimentos}

Agradecemos ao Programa de Pós-Graduação em Saúde Pública da Escola Nacional de Saúde Pública da Fundação Oswaldo Cruz (ENSP/Fiocruz), pelo apoio e incentivo à publicação científica de seus alunos, e à FAPERJ, por financiar a pesquisa da qual este artigo é parte.

\section{Referências}

AMARANTE P. (Coord). Loucos pela Vida: a trajetória da Reforma Psiquiátrica no Brasil. Rio de Janeiro: Fiocruz, 1995.

BORGES, C.F.; BAPTISTA, T.W.F. O modelo assistencial em saúde mental no Brasil: a trajetória da construção política de 1990 a 2004. Cad. Saúde Publica. Rio de Janeiro, v.24, n.2, p.456-468, 2008.

BRASIL. Ministério da Saúde. Conselho Nacional de Saúde. Comissão Organizadora da IV Conferência Nacional de Saúde Mental-Intersetorial. Relatório Final da IV Conferência Nacional de Saúde Mental: Intersetorial. Brasília: CNS, 2010.

BRASIL. Ministério da Saúde. Relatório Final da III Conferência Nacional de Saúde Mental. Brasília: MS, 2002.

BRASIL. Ministério da Saúde. Secretaria de Atenção à Saúde. Coordenação-Geral de Saúde Mental, Álcool e outras Drogas. Saúde Mental no SUS: as novas fronteiras da Reforma Psiquiátrica. Relatório de Gestão 2007-2010. Brasília: Ministério da Saúde, jan. 2011. 106p. BRASIL. Ministério da Saúde. Secretaria de Atenção à Saúde. Saúde Mental no SUS: acesso ao tratamento e mudança do modelo de atenção. Relatório de Gestão 2003-2006. Brasília: Ministério da Saúde, jan. 2007. 85p.

BRASIL. Ministério da Saúde. Secretaria de Vigilância em Saúde. A Lei Seca um ano depois. Boletim SVS em Rede. Brasília, ed. 66, nov 2009.

CELlARD, A. A análise documental. In: POUPART, J. et al. A pesquisa qualitativa: enfoques epistemológicos e metodológicos. Petrópolis: Vozes, 2008. p. 295-316. 
Humanos: locais de internação para usuários de drogas. Brasília: CFP, 2011. 200p.

COSTA, N.R. et al. Atores, políticas e instituições da Reforma Psiquiátrica brasileira. Ciência \& Saúde Coletiva. Rio de Janeiro, v.16, n.12, p.4576-4577, 2011.

COUTO. M.C.V.; DUARTE, C.S.; DELGADO, P.G.G. A saúde mental infantil na Saúde Pública brasileira: situação atual e desafios. Rev. Bras. Psiquiatr., v.30, n.4, p. 384-389, 2008.

DELGADO, P.G.G. Prefácio: o cuidado em saúde mental no território. In: SOUZA, M.E. Atenção em Saúde Mental. Belo Horizonte: Secretaria de Estado de Saúde, 2006. 238p.

LOBOSQUE, A.M. Experiências da Loucura. Rio de Janeiro: Garamond, 2001. 175p.

LOYOLA, C.M.D.; VIEIRA, M.A. Prestadores de serviço no campo da saúde mental: o público, o privado e o inefável da loucura. Rev. Latinoam. Psicopato. Fund., v. IX, n.1, p.114125, 2006.

MINAYO MCS. Violência e Saúde. Rio de Janeiro: Fiocruz, 2006.

MINAYO, M.C.S. A inclusão da violência na agenda da saúde: trajetória histórica. Ciência \& Saúde Coletiva. Rio de Janeiro, v. 11, supl., p. 1259-1267. Disponível em: <http://www. scielo.br/scielo.php?script=sci_arttext\&pid=S1413-81232006000500015\&lng=pt\&nrm =i so>. Acesso em: 08 jul. 2008.

MINAYO, M.C.S. Conceitos, teorias e tipologias de violência: a violência faz mal à saúde individual e coletiva. Em: NJAINE, K. et al (org.). Impactos da violência na saúde. 2 ed. Rio de Janeiro: Fiocruz, 2009. p. 21-42.

NJAINE, K et al, Rede de prevenção da violência: da utopia a ação. Ciência \& Saúde Coletiva, Sup. 11, p. 1313-1322, 2007.

PITTA, A.M.F. Um balanço da Reforma Psiquiátrica brasileira: instituições, atores e políticas. Ciência \& Saúde Coletiva. Rio de Janeiro, v.16, n.12, p.4570-4589, 2011.

RESENDE, H. Política de saúde mental no Brasil: uma visão histórica. Em: TUNDIS, S.A.; COSTA, N.R (orgs). Cidadania e loucura: políticas de saúde mental no Brasil. Petrópolis: Vozes, 1987. p. 15-73.

VASCONCELOS, E.M. (org.). Desafios politicos da reforma psiquiátrica brasileira. São Paulo: Hucitec, 2010.

\section{Documentos analisados}

BRASIL. Câmara dos Deputados. Projeto de Lei no 3.657-D, de 12 de setembro de 1989. Dispõe sobre a proteção e os direitos das pessoas portadoras de transtornos mentais e redireciona o modelo assistencial em saúde mental. Disponível em: http://www.camara. gov.br/proposicoesWeb/fichadetramitacao?idProposicao=20004. Acesso em 09 dez. 2012. 

Nacional sobre o Álcool, dispõe sobre as medidas para redução do uso indevido de álcool e sua associação com a violência e criminalidade, e dá outras providências. Diário Oficial da Uniāo. Brasília, DF, 23 maio 2007, Seção 1.

BRASIL. Ministério da Saúde. Decreto no 7.179, de 20 de maio de 2010. Institui o Plano Integrado de Enfrentamento ao Crack e outras Drogas, cria o seu Comitê Gestor, e dá outras providências. Diário Oficial da União. Brasília, DF, 21 de maio de 2010, Seção 1.

BRASIL. Ministério da Saúde. Decreto no 7.426, de 07 de janeiro de 2011. Dispõe sobre a transferência da Secretaria Nacional de Políticas sobre Drogas, do Conselho Nacional de Políticas sobre Drogas (CONAD) e da gestão do Fundo Nacional Antidrogas (FUNAD), do Gabinete de Segurança Institucional da Presidência da República para o Ministério da Justiça, bem como sobre remanejamento de cargos para a Defensoria Pública da União. Diário Oficial da União. Brasília, DF, 10 de janeiro de 2011. Seção 1.

BRASIL. Ministério da Saúde. Lei no 10.216, de 4 de junho de 2001. Dispõe sobre a proteção e os direitos das pessoas portadoras de transtornos mentais e redireciona o modelo assistencial em saúde mental. Diário Oficial da União. Brasília, DF, 9 de junho de 2001. Seção 1.

BRASIL. Ministério da Saúde. Lei no 10.708, de 31 de julho de 2003. Institui o auxílioreabilitação psicossocial para pacientes acometidos de transtornos mentais egressos de internações. Diário Oficial da Uniāo. Brasília, DF, 10 de agosto de 2003. Seção 1.

BRASIL. Ministério da Saúde. Lei no 11.343, de 23 de agosto de 2006. Institui o Sistema Nacional de Políticas Públicas sobre Drogas (Sisnad); prescreve medidas para prevenção do uso indevido, atenção e reinserção social de usuários e dependentes de drogas; estabelece normas para repressão à produção não autorizada e ao tráfico ilícito de drogas; define crimes e dá outras providências. Diário Oficial da União. Brasília, DF, 24 de agosto de 2006. Seção 1.

BRASIL. Ministério da Saúde. Lei no 12.318, de 30 de agosto de 2010. Dispõe sobre a alienação parental e altera o art. 236 da Lei no 8.069, de 13 de julho de 1990. Diário Oficial da União. Brasília, Df, 31 de agosto de 2010. Seção 1.

BRASIL. Ministério da Saúde. Lei no 12.461, de 26 de julho de 2011. Altera a Lei no 10.741, de $1^{\circ}$ de outubro de 2003, para estabelecer a notificação compulsória dos atos de violência praticados contra o idoso atendido em serviço de saúde. Diário Oficial da União. Brasília, DF, 27 de julho de 2011.

BRASIL. Ministério da Saúde. Lei no 11.705, de 19 de junho de 2008. Altera a Lei no 9.503, de 23 de setembro de 1997, que institui o Código Brasileiro de Trânsito, e a Lei no 9.294, de 15 de julho de 1996, que dispõe sobre as restrições do uso e à propaganda de produtos fumígeros, bebidas alcoólicas, medicamentos, terapias, e defensivos agrícolas, nos termos do $\$ 4^{\circ}$. Do art. 220 da Constituição Federal, para inibir o consumo de bebida alcoólica 
por condutor de veiculo automotor e dá outras providencias. Disponível em: <http://www. planalto.gov.br/ccivil_03/_Ato2007-2010/2008/Lei/L11705.htm> Acesso em: 10 jul 2010. BRASIL. Ministério da Saúde. Portaria GM/MS no 737, de 16 de maio de 2001. Política Nacional de Redução da Morbimortalidade por Acidentes e Violências. Diário Oficial da União. Brasília, DF, 17 de maio de 2002. Disponível em: http://www.mp.rs.gov.br/infancia/ legislacao/id3072.htm. Acesso em: $07 \mathrm{dez} 2012$.

BRASIL. Ministério da Saúde. Portaria no 336, de 19 de fevereiro de 2002. Estabelece CAPS I, CAPS II, CAPS III, CAPS i II e CAPS ad II. Diário Oficial da União. Brasília, DF, 20 de fevereiro de 2002. Seção 1. Disponível em: http://www.ccs.saude.gov.br/saudemental/ legislacao.php>. Acesso em: 07 dez 2012.

BRASIL. Ministério da Saúde. Portaria Conjunta SGTES/MS nº 6, de 17 de setembro de 2010. Institui no âmbito do Programa de Educação pelo Trabalho para a Saúde (PETSaúde), o PET-Saúde/Saúde Mental. Diário Oficial da União. Brasília, DF, 2010. Disponível em: <http://www.ccs.saude.gov.br/saudemental/legislacao.php $>$. Acesso em: $07 \mathrm{dez} 2012$.

BRASIL. Ministério da Saúde. Portaria GM no 2.391, de 26 de dezembro de 2002. Regulamenta o controle das internaçôes psiquiátricas involuntárias (IPI) e voluntárias (IPV) de acordo com o disposto na Lei no 10.216 , de 6 de abril de 2002, e os procedimentos de notificação da Comunicação das IPI e IPV ao Ministério Público pelos estabelecimentos de saúde, integrantes ou não do SUS. Diário Oficial da União. Brasília, DF, 27 de dezembro de 2002. Disponível em: http://www.ccs.saude.gov.br/saudemental/legislacao.php. Acesso em: $07 \mathrm{dez} 2012$.

BRASIL. Ministério da Saúde. Portaria GM no 251, de 31 de janeiro de 2002. Estabelece diretrizes e normas para a assistência hospitalar em psiquiatria, reclassifica os hospitais psiquiátricos, define e estrutura, a porta de entrada para as internações psiquiátricas na rede do SUS e dá outras providências. Diário Oficial da União. Brasília, DF, 01 de fevereiro de 2002. Disponível em: http://www.ccs.saude.gov.br/saudemental/legislacao.php> Acesso em: $07 \mathrm{dez} 2012$.

BRASIL. Ministério da Saúde. Portaria GM/MS no 936, de 19 de maio de 2004. Dispõe sobre as regras e critérios para apresentação, monitoramento, acompanhamento e avaliação de projetos do Programa de Apoio ao Desenvolvimento Institucional do Sistema Único de Saúde (PROADI-SUS). Diário Oficial da União. Brasília, DF, 20 de maio de 2004. Disponível em: http://www.ccs.saude.gov.br/saudemental/legislacao.php. Acesso em: $07 \mathrm{dez} 2012$.

BRASIL. Ministério da Saúde. Portaria GM/MS no 1.027, de 01 de julho de 2005. Aprova as Normas de Funcionamento e Credenciamento/Habilitação dos Serviços Hospitalares de Referência para a Atenção Integral aos Usuários de Álcool e outras Drogas. Diário Oficial da União. Brasília, DF, 02 de julho de 2005. Disponível em: http://www.ccs.saude.gov.br/ saudemental/legislacao.php. Acesso em: $07 \mathrm{dez} 2012$. 
BRASIL. Ministério da Saúde. Portaria GM/MS no 1.028, de 01 de julho de 2005. Determina que as ações que visam à redução de danos sociais e à saúde, decorrentes do uso de produtos, substâncias ou drogas que causem dependência, sejam reguladas por esta Portaria. Diário Oficial da União. Brasília, DF, 03 de julho de 2005. Disponível em: http:// www.ccs.saude.gov.br/saudemental/legislacao.php. Acesso em: $07 \mathrm{dez} 2012$.

BRASIL. Ministério da Saúde. Portaria GM/MS no 1.190, de 04 de junho de 2009. Institui o Plano Emergencial de Ampliação do Acesso ao Tratamento e Prevenção em Álcool e outras Drogas no Sistema Único de Saúde - SUS (PEAD 2009-2010) e define suas diretrizes gerais, açôes e metas. Diário Oficial da União. Brasília, DF, 12 de junho de 2010. Disponível em: http://www.ccs.saude.gov.br/saudemental/legislacao.php

BRASIL. Ministério da Saúde. Portaria GM/MS no 1.876, de 14 de agosto de 2006. Institui Diretrizes Nacionais para Prevenção do Suicídio, a serem implantadas em todas as unidades federadas, respeitadas as competências das três esferas de gestão. Diário Oficial da Uniāo. Brasília, DF, de 15 de agosto de 2006. Disponível em: http://www.ccs.saude.gov.br/ saudemental/legislacao.php. Acesso em: 07 dez 2012.

BRASIL. Ministério da Saúde. Portaria GM/MS no 2.542, de 22 de dezembro de 2005. Institui Grupo de Trabalho com o objetivo de elaborar e implantar a Estratégia Nacional de Prevenção ao Suicídio. Diário Oficial da União. Brasília, DF, 27 de dezembro de 2005. Disponível em: http://www.ccs.saude.gov.br/saudemental/legislacao.php. Acesso em: 07 dez 2012.

BRASIL. Ministério da Saúde. Portaria GM/MS no 2.669, de 03 de novembro de 2009. Estabelece as prioridades, objetivos, metas e indicadores de monitoramento e avaliação do Pacto pela Saúde, nos componentes pela Vida e de Gestão, e as orientações, prazos e diretrizes do seu processo de pactuação para o biênio 2010 - 2011. Diário Oficial da União. Brasília, DF, 04 de novembro de 2010. Disponível em: http://www.ccs.saude.gov.br/saudemental/ legislacao.php. Acesso em: $07 \mathrm{dez} 2012$.

BRASIL. Ministério da Saúde. Portaria GM/MS no 2.607, de 10 de dezembro de 2004. Aprova o Plano Nacional de Saúde/PNS - Um Pacto pela Saúde no Brasil. Diário Oficial da União. Brasília, DF, 11 de dezembro de 2004. Disponível em: http://www.ccs.saude.gov.br/ saudemental/legislacao.php. Acesso em: 07 dez 2012.

BRASIL. Ministério da Saúde. Portaria GM/MS no 2.759, de 25 de outubro de 2007. Estabelece diretrizes gerais para a Política de Atenção Integral à Saúde Mental das Populações Indígenas e cria o Comitê Gestor. Diário Oficial da Uniāo. Brasília, DF, 27 de outubro de 2007. Disponível em: http://www.ccs.saude.gov.br/saudemental/legislacao.php. Acesso em: $07 \mathrm{dez} 2012$. 
BRASIL. Ministério da Saúde. Portaria GM/MS no 2.841, de 20 de setembro de 2010.

Institui no âmbito do Sistema Único de Saúde - SUS, o Centro de Atenção Psicossocial de Álcool e outras Drogas - 24 horas - CAPS AD III. Diário Oficial da União. Brasília, DF, 23 de setembro de 2010. Disponível em: http://www.ccs.saude.gov.br/saudemental/legislacao. php. Acesso em: 07 dez 2012.

BRASIL. Ministério da Saúde. Portaria GM/MS no 2.842, de 20 de setembro de 2010. Aprova as Normas de Funcionamento e Habilitação dos Serviços Hospitalares de Referência para a Atenção Integral aos Usuários de Álcool e outras Drogas - SHRad. Diário Oficial da União. Brasília, DF, 23 de setembro de 2010. Disponível em: http://www.ccs.saude.gov.br/ saudemental/legislacao.php. Acesso em: $07 \mathrm{dez} 2012$.

BRASIL. Ministério da Saúde. Portaria GM/MS no 2.843, de 20 de setembro de 2010. Cria, no âmbito do Sistema Único de Saúde - SUS, os Núcleos de Apoio à Saúde da Família Modalidade 3 - NASF 3, com prioridade para a atenção integral para usuários de crack, álcool e outras drogas. Diário Oficial da União. Brasília, DF, 23 de setembro de 2010. Disponível em: http://www.ccs.saude.gov.br/saudemental/legislacao.php. Acesso em: 07 dez 2012.

BRASIL. Ministério da Saúde. Portaria GM/MS no 4.135, de 17 de dezembro de 2010. Destina recursos financeiros emergenciais para ações de qualificação da Rede de Atenção Integral em Álcool e outras Drogas em Municípios de pequeno porte, no âmbito do Plano Integrado de Enfrentamento ao Crack e outras Drogas. Diário Oficial da União. Brasília, DF, 20 de dezembro de 2010. Disponível em: http://www.ccs.saude.gov.br/saudemental/ legislacao.php. Acesso em: $07 \mathrm{dez} 2012$.

BRASIL. Ministério da Saúde. Portaria GM/MS no 4.252, de 29 de dezembro de 2010. Destina recursos financeiros emergenciais para ações de qualificação da Rede de Atenção Integral em Álcool e outras Drogas, no âmbito do Decreto no 7.179, de 20 de maio de 2010. Diário Oficial da Uniāo. Brasília, DF, 30 de dezembro de 2010. Disponível em: http://www. ccs.saude.gov.br/saudemental/legislacao.php. Acesso em: 07 dez 2012.

BRASIL. Ministério da Saúde. Portaria GM/MS n¹54, de 24 de janeiro de 2008. Cria os Núcleos de Apoio à Saúde da Família - NASF. Diário Oficial da União. Brasília, DF, 26 de janeiro de 2008. Disponível em: http://www.ccs.saude.gov.br/saudemental/legislacao.php. Acesso em: $07 \mathrm{dez} 2012$.

BRASIL. Ministério da Saúde. Portaria Interministerial PR/MS no 1.055, de 17 de maio de 2006. Institui Grupo de Trabalho para viabilizar a constituição do Núcleo Brasileiro de Direitos Humanos e Saúde Mental. Diário Oficial da Uniāo. Brasília, DF, de 18 de maio de 2006. Disponível em: http://www.ccs.saude.gov.br/saudemental/legislacao.php. Acesso em: $07 \operatorname{dez} 2012$. 
BRASIL. Ministério da Saúde. Portaria no 3.088, de 23 de dezembro de 2011. Institui a Rede de Atenção Psicossocial para pessoas com sofrimento ou transtorno mental e com necessidades decorrentes do uso de crack, álcool e outras drogas, no âmbito do Sistema Único de Saúde. Diário Oficial da União. Brasília, DF, de 26 de dezembro de 2011. Disponível em: http://bvsms.saude.gov.br/bvs/saudelegis/gm/2011/anexo/anexo_prt3099_23_12_2011. pdf. Acesso em: 07 dez 2012.

BRASIL. Ministério da Justiça. Resolução CNJ/MJ no 113, de 20 de abril de 2010. Dispõe sobre o procedimento relativo à execução de pena privativa de liberdade e de medida de segurança, e dá outras providências. Diário Oficial da União. Brasília, DF, 25 de abril de 2010. Disponível em: http://www.ccs.saude.gov.br/saudemental/legislacao.php. Acesso em: 07 dez 2012

BRASIL. Ministério da Justiça. Resolução CNPCP/MJ no 4, de 29 de abril de 2010. Diário Oficial da União. Brasília, DF, abril de 2010. Disponível em: http://www.ccs.saude.gov.br/ saudemental/legislacao.php. Acesso em: 07 dez 2012.

BRASIL. Ministério da Saúde. Conselho Nacional de Saúde. Resolução no 196, de 10 de outubro de 1996. Dispóe sobre a pesquisa com seres humanos. Diário Oficial da União. Brasília, DF, 13 de outubro de 1996. Seção 1.

\section{Notas}

${ }^{1}$ Disponível em < http://www.ccs.saude.gov.br/saudemental/legislacao.php $>$.

${ }^{2}$ F.C. Valadares trabalhou na concepção, análise e interpretação dos dados e redação do artigo. E.R. de Souza trabalhou na concepção, redação do artigo e aprovação final da versão a ser publicada. 


\section{Abstract}

Analysis of the insertion of the issue of violence in Brazilian Mental Health Policies based on its legal frameworks (2001-2011)

The paper aims to describe and analyze the process of inserting the issue of violence in the legal frameworks of the Brazilian public politics on mental health, with a view to contribute to the identification of challenges and dilemmas in this area. We conducted a documental analysis of laws, decrees and orders issued by the Health Ministry and official publications of this Coordination of Mental Health Ministry issued from January 2001 to December 2011. We observed the consolidation of three trends in these documents: Violence and psychiatric institution (2001-2003), marked by the consolidation of parameters guiding deinstitutionalization policies and ensuring the rights of individuals with mental disorders; violence, the territory and its demands (2004-2008), where attention to social vulnerabilities and integral health care are identified; violence and the challenge of harmful use of alcohol and other drugs (2009-2011), showing that risk situations and violence associated with this use sharpen tensions between conservative political forces in the field of social policies. We conclude that mental health policies were adapted to the emerging social problems in the country, with a view to enhancing the quality of life and prevention of violence.

> Key words: violence; mental health; mental health policies; document analysis; Brazil. 